\title{
Crystal Structures of Fsa2 and Phm7 Catalyzing [4 + 2] Cycloaddition Reactions with Reverse Stereoselectivities in Equisetin and Phomasetin Biosynthesis
}

Changbiao Chi, ${ }^{1+}$ Zhengdong Wang, ${ }^{1,}{ }^{\ddagger}$ Tan Liu, ${ }^{1}$ Zhongyi Zhang, ${ }^{1}$ Huan Zhou, ${ }^{2}$ Annan Li, ${ }^{1}$ Hongwei Jin, ${ }^{1}$ Hongli Jia,${ }^{1}$ Fuling Yin, ${ }^{1}$ Donghui Yang,,${ }^{1}$ and Ming Ma ${ }^{1, *}$

${ }^{1}$ State Key Laboratory of Natural and Biomimetic Drugs, School of Pharmaceutical Sciences, Peking University, 38 Xueyuan Road, Haidian District, Beijing 100191, China

${ }^{2}$ Shanghai Synchrotron Radiation Facility, Shanghai Advanced Research Institute, Chinese Academy of Sciences, 239 Zhangheng Road, Pudong District, Shanghai 201204, China

These authors contributed equally

*To whom correspondence should be addressed: Ming Ma, E-mail: mma@bjmu.edu.cn 


\section{Table of Contents}

The optimized gene sequences of $f s a 2$ and $p h m 7$ for expression in $E$. coli

Table S1. Plasmids used in this study .S5

Table S2. The X-ray data collection and refinements statistics .S6

Figure S1. Natural pericyclases catalyzing $[4+2]$ and $[6+4]$ cycloaddition reactions in the biosynthesis of natural products

Figure S2. The SDS-PAGE analysis of Se-Fsa2 and Phm7 ...................................................

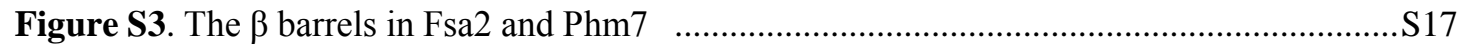

Figure S4. Structural superimposition of $\mathrm{N}$ - and C-terminal $\beta$ barrels in Fsa2 or Phm7 ...........S18

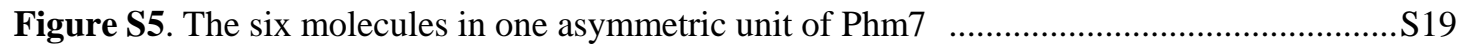

Figure S6. Sequence alignment of Fsa2, Phm7, and CghA ....................................................S20

Figure S7. Structural superimpositions of N- and C-terminal $\beta$ barrels of Fsa2 with PyrI4, AbyU, and AbmU

Figure S8. The two glycerol molecules in the active site of Fsa2 and their interactions with Ser226

Figure S9. The products modeling into the active sites of Fsa2 and $\mathrm{Phm} 7$

Figure S10. Comparison of the modeled 6 within the active site of $\mathrm{Phm} 7$ and the complex structure of CghA with its product Sch210972

Figure S11. The molecular dynamics simulation of 5-bound Fsa2 S25

Figure S12. The molecular dynamics simulation of 5-bound Phm7 S26

Reference S27 
The optimized gene sequence of $f s a 2$ and $p h m 7$ for expression in E. coli

The optimized gene sequence of $f s a 2$ :

ATGTCCAACGTGACCGTATCCGCATTCACGGTCGATAAGAGCATCAGCGAGGAGCATGTCCTGCCTAG CAGCTTCATTCCGGGTAGCGGTAACATCTTCCCAAAGTTCACCTCCGCAATCCCAAAGACGGCTTGGG AGCTGTGGTACTTTGACGGTATCAGCAAAGACGACAAAAGCTCCATCGTCATCGGTGTGACCCGTAAC GCGGAGGGTCTGAAACATGGTGGTTTCAAAGTGCAGGTCTTCGTGATCTGGGCAGACGAACGTACGT GGCACCGTGACCTGTTCTTCCCGGAATCCGTGGTGTCTATCAACGAATCCGGTGTAACCGACGGTATTT GGAAAGACGCTACGAGCAACAGCTCTATCAGCTTCAGCTGCGCTGGTGATCTGTCCAAAGCATCCCTG GTGTTCGACGTGCCGGGCGTGGTACAGGGTGACATGCACCTGGAAGCTCTGCCAGGTGATACTGGTCT GGATACTGACGCACGTCTGGGTCCGTCTGTTTACTATGTTCGTCCGATCGGTCGTGCTTCTGTAAAAGC CCAGCTGTCTCTGTACAGCTCCGACGCTACTGCGGCGGAACAATTTTCCCTGGGTACTTCCGCGAATG GTGGTATGGATCGTGTTTGGTCCCCGCTGTCTTGGCCGCAAGTAATGACTGAATCTTACTACCTGCGCA CTCAGGTTGGTCCGTACGCCATGCAAATCATGCGTATTTTTCCGCCGGCCGGTTCTGAAGATCAGCCGT CTACCATGGCGCGTCTGTACCGCGAAGGCCAGCTGGTTTGTGTTGCGCAGCACGTTGTAACTCGCGAA GATGCGCTGATGACCCACGATTCTCTGATTCTGTCTAAACAGGATAACTCCGACTCTGAAGACGTTGTT ACCGGCGGCTATCGTGATAAAAACACCGGCTATACCGTTGAATTTGTTGAAAAAGGCAACGAGGGCCA GCGTTGGAAATTTCAGGTACGCCACGAACGCATCATTTGGAACACCCCGACCTCTCGCCCTGGCCCGG ATGCCACCGGCAATACCGGCTTCGTTGAAGTTCTGTGCGGCGGCACCATTGGCGAATCTTATGAAGGC GTTGGCACTGGCGGCCAGTGTGAACTGTCTAA

The optimized gene sequence of $p h m 7$ :

ATGAGCGAACCGACCTCAAGCAGTAGTCTGGATATTACCAGTAATTGCATTATTGAAACCCCGCTGCAG CCGAGCGATTTTCTGCCTAAAAGTGCCAATCTGTTTCCGAAATTTCCGGAACGCATTAGCGTTGATAGC TGGGAACTGTGGGAATTTGATACCTTTGATACCAATGGTAGTGTTGCATTTGGTTGCAGTCTGTATCGT GATGCACGTGGCGTTGAACAGGGCGGTTTTCATGCCGAAGTTAATGCCCTGTGGCCGGATGGTACCCA TTGGGGTGAAACCCTGTATTTTGCCGTTAGCGAAGTTGTTGAAAATAGTGATGGTACCACCGGTGGCA AATGGCTGAGTAAAGATGGTGGTAGCATTACCTTTCATATTGCCAGTGATTATACCGCCGCCGCACTGG ATTTTAATGTGCCGGGTAAAGTTAGCGGTACCATGGAACTGCGCAATCATGCCAATGTTAGTCCGACCA GTAATCTGCCGGCAAGTGATGCCGAAGCACAGTTATGTCCGGGCGTGTATTATACCTTTCCGATGGGTC CGGTGGCAACCTCAGTGACAGCAACATTTTCAAGCGTTGGCGCCAATGGCGAAAGCCGTGAACTGTT 
TATTAGTAGCGGCTATGGCGGTATGGTTCGTGGCTGGTCAGCCAGACCTTGGCCTACATTCATGAATGA TGCCTATTATGTTGTTGCCCAGGTGGGCCCGTATATGCTGCAAATTCTGCGCACCCTGGGCAGTGTGTT TGTGCAACATAAACCGTTTGCAGTTGCCCGCCTGTATCTGGATGGCTCACTGGTTAGTGCAGCCAATAC CGTTGTGGGCGATGAACTGACCGCACATGCAGATGATGTTAAAGGTGACGCAGTTCGCCTGACCAAA GTGCAGCCTGATGAAAAAAGCCAGGGCCTGAGCGGTAAATTTCGTGATGGCAATGTTGGCTATGTGCT GGAATTTGCAAAAAAGGATAGTGAACATGGTTGGACCTTTCAGATTAGCCATAAACGTGCAGTTTGGA GTGAACCGACCAGTGCCCCTGGTCCTGATGGTACAGGTAAAAGTGGCTGGATTGAAGCCATTAGCGGC GGTGCAAAAGGCGAAAATTATGAAGGTCATGGCTTTGGTGGTCAGCTGCAGATTCCGGTGCCGTAA 
Table S1. Plasmids used in this study

\begin{tabular}{llc}
\hline Plasmids & Description & Sources \\
\hline pMM4005 & Modified pET28b(+) containing $f s a 2$ gene for protein production & This work \\
pMM4006 & Modified pET28b(+) containing $p h m 7$ gene for protein production & This work \\
\hline
\end{tabular}


Table S2. The X-ray data collection and refinements statistics

\begin{tabular}{|c|c|c|}
\hline & Fsa2 & Phm7 \\
\hline \multicolumn{3}{|l|}{ Data collection } \\
\hline Wavelength $(\AA)$ & 1.54056 & 1.54056 \\
\hline Space group & $P 2{ }_{1} 2_{1} 2_{1}$ & $P 2_{1}$ \\
\hline \multicolumn{3}{|l|}{ Unit cell } \\
\hline$a, b, c(\AA)$ & $85.0,82.4,48.2$ & $91.2,150.5,100.0$ \\
\hline$\alpha, \beta, \gamma\left(^{\circ}\right)$ & $90.0,90.0,90.0$ & $90.0,96.9,90.0$ \\
\hline \multirow[t]{2}{*}{ Resolution range $(\AA)$} & $13.59-2.00$ & $13.42-2.00$ \\
\hline & $(2.07-2.00)$ & $(2.07-2.00)$ \\
\hline Unique reflections & $23,436(2,349)$ & $179,300(17,930)$ \\
\hline$R_{\text {merge }}{ }^{\mathrm{a}}$ & $0.09(0.363)$ & $0.130(0.423)$ \\
\hline$I / \sigma I$ & $26.86(7.15)$ & $11.33(3.43)$ \\
\hline Completeness (\%) & $99.3(99.3)$ & $99.5(99.9)$ \\
\hline Average redundancy & $12.6(13.1)$ & $6.7(6.9)$ \\
\hline \multicolumn{3}{|l|}{ Structure refinements } \\
\hline Resolution range $(\AA)$ & $13.60-2.00$ & $13.43-2.00$ \\
\hline$R_{\text {work }}^{\mathrm{b}} / R_{\text {free }}^{\mathrm{c}}$ & $0.1761 / 0.2139$ & $0.1731 / 0.2098$ \\
\hline Number of protein atoms & 2839 & 17039 \\
\hline Number of water atoms & 318 & 1883 \\
\hline RMSD $^{d}$ bond lengths $(\AA)$ & 0.007 & 0.019 \\
\hline RMSD bond angles $\left({ }^{\circ}\right)$ & 0.896 & 1.844 \\
\hline Average B-factors $\left(\AA^{2}\right)$ & 21.7 & 24.0 \\
\hline \multicolumn{3}{|c|}{ Ramachandran plot ${ }^{\mathrm{e}}$ (residues, \%) } \\
\hline Most favored & 95.87 & 96.04 \\
\hline Additional allowed & 4.13 & 3.56 \\
\hline Outliers & 0.00 & 0.40 \\
\hline Protein Data Bank entry & 7DMN & 7DMO \\
\hline
\end{tabular}

${ }^{\mathrm{a}} R_{\text {merge }}=\sum_{\mathrm{hk} l} \sum_{i}\left|I_{i}(h k l)-<I(h k l)>\right| / \sum_{h k l} \sum_{i} I_{i}(h k l)$, where $I_{i}(h k l)$ is the intensity of an 
observation and $\langle I(h k l)\rangle$ is the mean value for its unique reflection. Summations are over all reflections.

${ }^{\mathrm{b}} R_{\text {work }}=\sum_{h}\left|F_{o}(h)-F_{c}(h)\right| / \sum_{h} F_{o}(h)$, where $F_{o}$ and $F_{c}$ are the observed and calculated structure factor amplitudes, respectively.

${ }^{\mathrm{c}} R_{\text {free }}$ was calculated with $5 \%$ of the data excluded from the refinement.

${ }^{\mathrm{d}} \mathrm{RMSD}$, root mean square deviation from ideal values.

${ }^{\mathrm{e}}$ The categories were defined by Molprobity. 
Figure S1. Natural pericyclases catalyzing $[4+2]$ and $[6+4]$ cycloaddition reactions in the biosynthesis of natural products. These biosynthetic pericyclases include Sol5 in solanapyrone B biosynthesis, ${ }^{1} \mathrm{UcsH}$ in UCS1025A biosynthesis, ${ }^{2}$ PoxQ in oxaleimide A biosynthesis, ${ }^{3}$ Bet1 in betaenone biosynthesis, ${ }^{4} \mathrm{PvhB}$ in varicidin B biosynthesis, ${ }^{5} \mathrm{CghA}$ in Sch210972 biosynthesis, ${ }^{6}$ MycB in myceliothermophin B biosynthesis, ${ }^{7}$ LovB in lovaststin biosynthesis, ${ }^{8}$ IccD in ilicicolin biosynthesis, ${ }^{9} \mathrm{ChaB}$ in chaetolivacines B biosynthesis, ${ }^{10} \mathrm{StmD}$ in streptoseomycin biosynthesis, ${ }^{11}$ NgnD in nargenicin biosynthesis, ${ }^{11}$ Epil in fusaricide biosynthesis, ${ }^{12}$ LepI in leporin $\mathrm{C}$ biosynthesis, ${ }^{13,14} \mathrm{IdmH}$ in indanomycin biosynthesis, ${ }^{15} \mathrm{CrcS}$ in catharanthine biosynthesis, ${ }^{16}$ TitabS in tabersonine biosynthesis, ${ }^{16} \mathrm{AbmU}$ in neoabyssomicin B biosynthesis, ${ }^{17} \mathrm{AbyU}$ in abyssomicin C biosynthesis, ${ }^{18} \mathrm{PhqE}$ in Paraherquamide A biosynthesis, ${ }^{19} \mathrm{MalC}$ in malbrancheamide biosynthesis, ${ }^{20} \mathrm{PyiF}$ in pyrichalasin $\mathrm{H}$ biosynthesis, ${ }^{3} \mathrm{CcsF}$ in cytochalasin $\mathrm{K}$ biosynthesis, ${ }^{21} \mathrm{VstJ}$ in versipelostatin biosynthesis, ${ }^{22} \mathrm{SpnF}$ in spinosyn biosynthesis, ${ }^{23} \mathrm{PyrE} 3$ and PyrI4 in pyrroidomycin biosynthesis, ${ }^{24} \mathrm{TbtD}$ in thiomuracin GZ biosynthesis, ${ }^{25} \mathrm{TcIM}$ in thiocillins biosynthesis, ${ }^{26} \mathrm{PbtD}$ in GE2270A biosynthesis, ${ }^{27}$ EupfF in neosetophomone B biosynthesis, ${ }^{28}$ SorD in spirosorbicillinol B biosynthesis, ${ }^{29} \mathrm{MaDA}$ in chalcomoracin biosynthesis, ${ }^{30}$ AsR5 in xenovulene A biosynthesis, ${ }^{31}$ riboflavin synthase in riboflavin biosynthesis. ${ }^{32}$ 
<smiles>C/C=C\C=C/CC/C=C/c1cc(OC)c(C=O)c(=O)o1</smiles><smiles>COc1ccoc(=O)c1C=O</smiles>

Sol5<smiles>CC(C)[C@H]1C(C)C=C[C@@H]2CCCC[C@H]12</smiles><smiles>C1CCCC1</smiles>

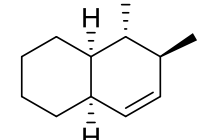

Solanapyrone B<smiles>C/C=C\C=C/CC/C=C/C(=O)C1=C[C@H]2[C@H](C)CCN2C(=O)C1=O</smiles><smiles>CC1CCN2C(=O)C(C(=O)[C@H]3[C@@H](C)C=C[C@H]4CCCC[C@@H]43)=C[C@@H]12</smiles>
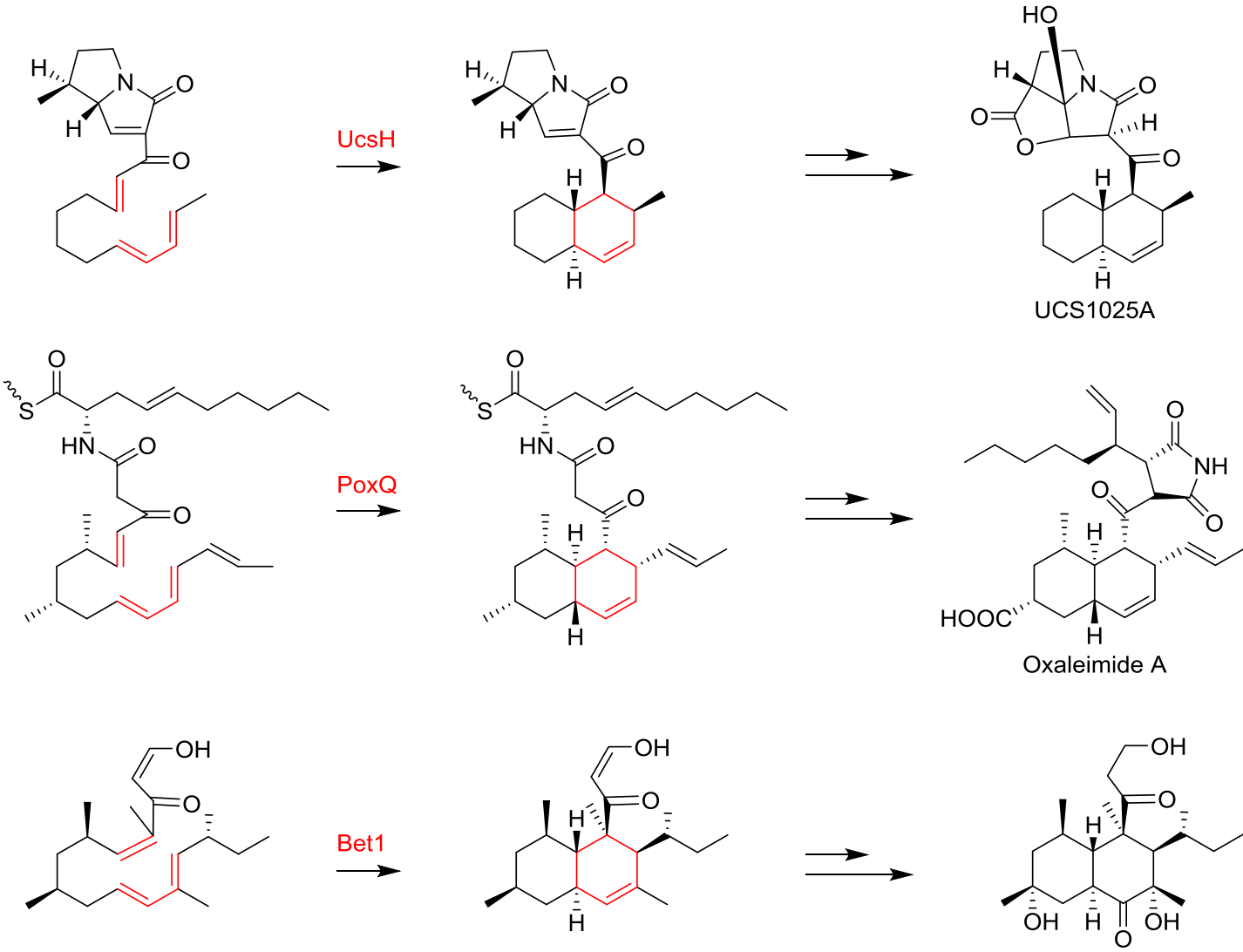

Betaenone B

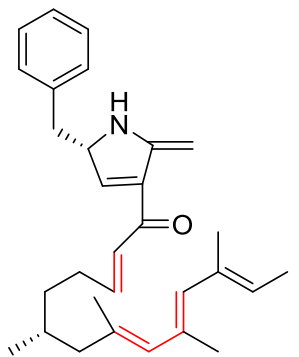

ChaB
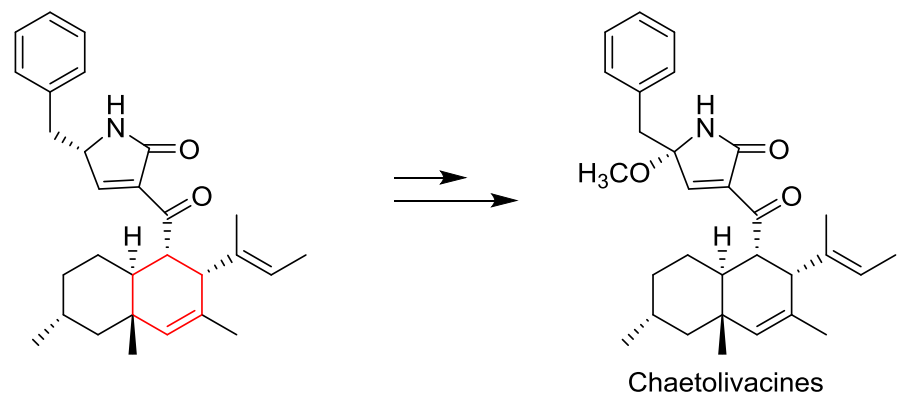

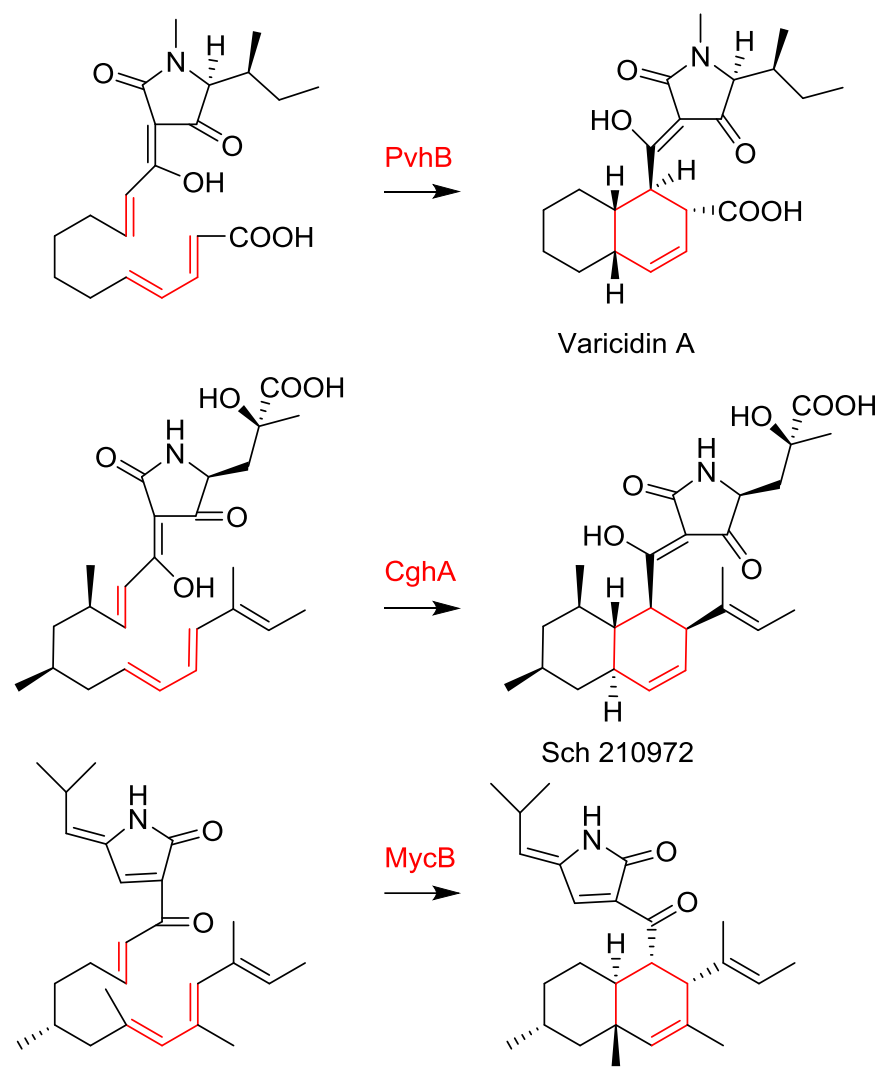

Myceliothermophin E<smiles>C/C=C\C=C/C[C@H](C)CC/C=C/C(=O)SC</smiles>

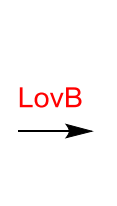<smiles>CSC(=O)C1C(C)C=CC2C[C@@H](C)CC[C@@H]21</smiles>

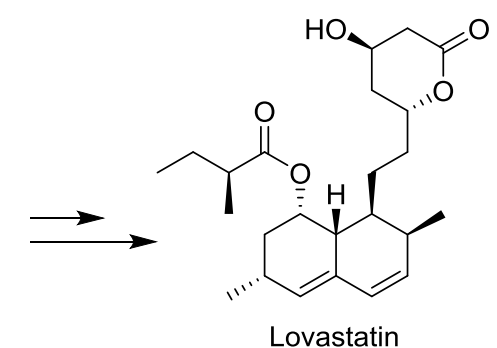

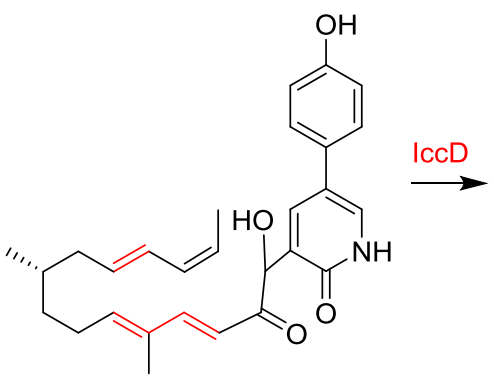<smiles>C/C=C/[C@H]1C(C(=O)c2c(O)c(-c3ccc(O)cc3)c[nH]c2=O)C=C[C@@H]2CC[C@@H](C)C[C@@H]12</smiles><smiles>C/C=C/[C@@H]1[C@H](C(=O)c2c(O)c(-c3ccc(O)cc3)c[nH]c2=O)C=C[C@@H]2CC[C@H](C)C[C@@H]21</smiles> 

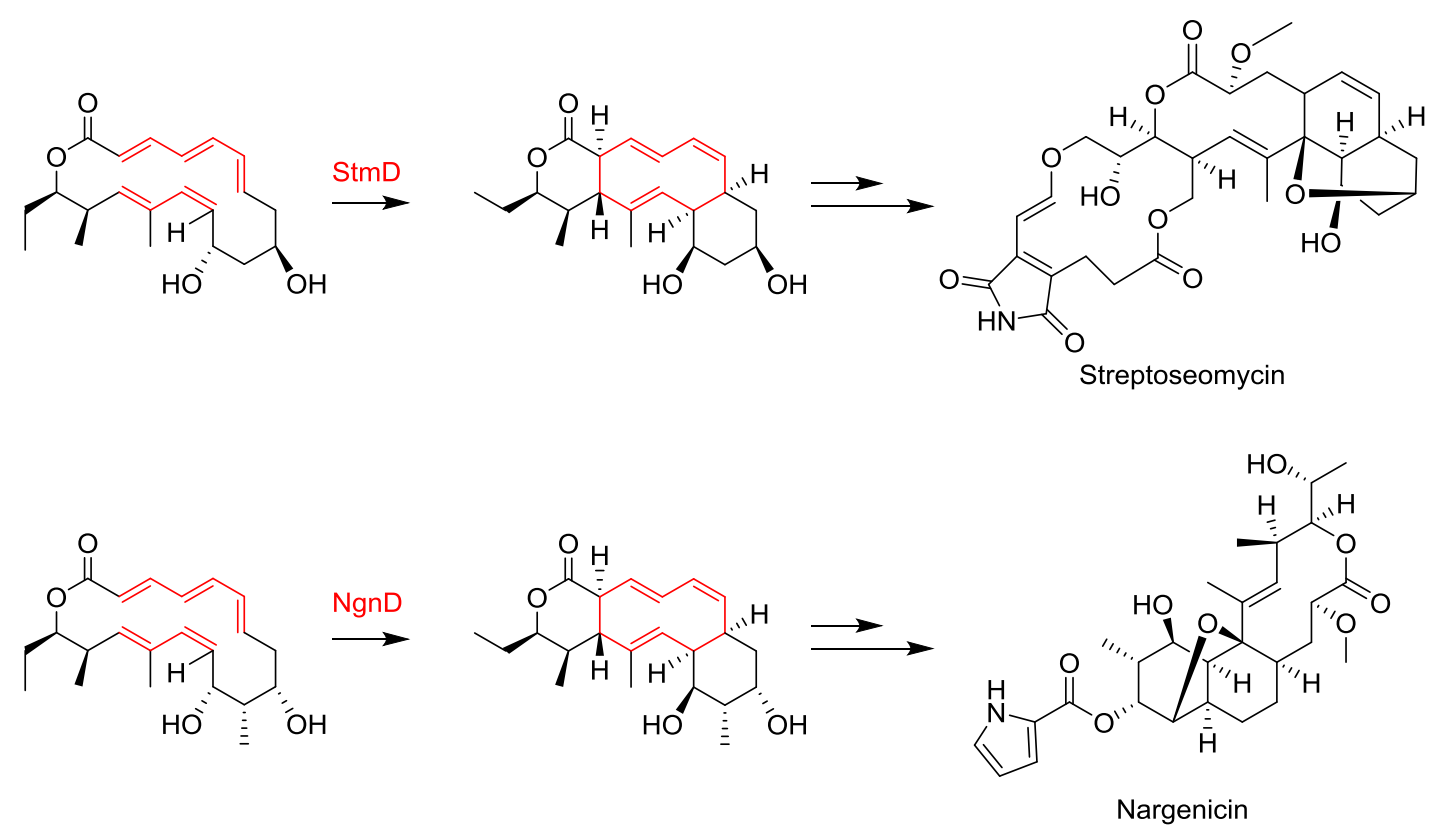<smiles>C/C=C/C[C@H](C)C[C@H](C)C=C1C(=O)C=CNC1=O</smiles><smiles>C/C=C/C=C/CCC[C@H](C)C=C1C(=O)NC=C(c2ccccc2)C1=O</smiles>

Leporin C 


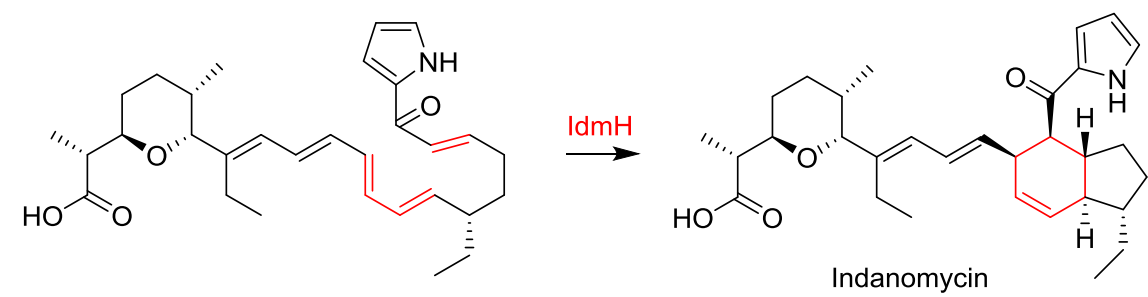<smiles></smiles><smiles></smiles><smiles>CC=C(C)C(=O)CN1CC=CC=C(CC)Nc2ccccc2CC1</smiles><smiles>CCC12C=CCN3CCc4ccccc4NC1=C(C(=O)OC)CC32CC</smiles><smiles>C=C1OC(=O)C2C(=O)CC[C@H](C)C(=O)C(=CC=CC(C)=CC)CC12</smiles><smiles>CC1=CC2/C=C\C(=O)[C@@H](C)CCC(=O)C(=O)C2=C(O)C12CC(C)C(=O)O2</smiles>

Tabersonine<smiles>C/C=C\C=C/C=C/C(=O)C(C)CC(C)C(=O)C1C(=O)O/C(=C/C)C1O</smiles>

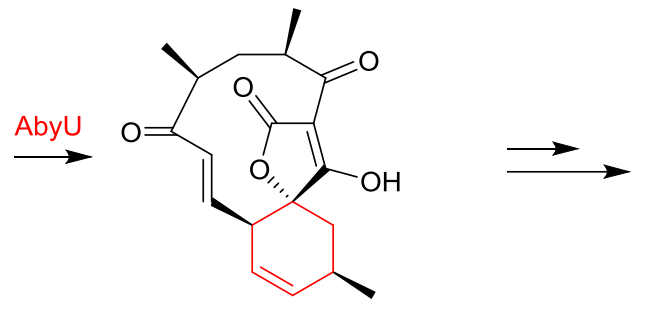<smiles>C=CC(C)(C)c1[nH]c2ccccc2c1CC1=NC(O)=C2C(C)CCN2C1</smiles>

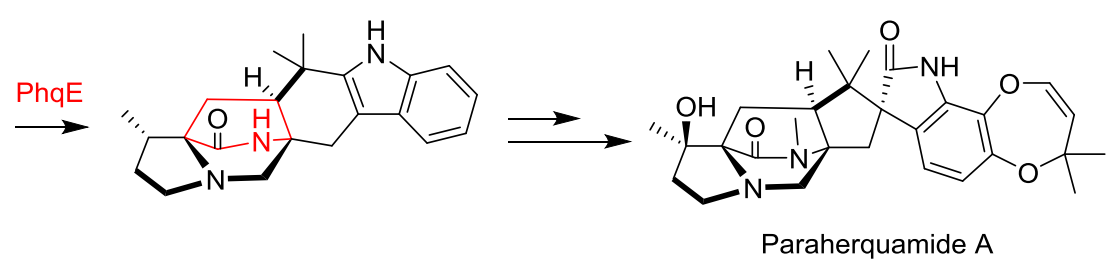<smiles>C=CC(C)(C)c1[nH]c2ccccc2c1CC1=NC(O)=C2CCCN2C1</smiles><smiles>CC1(C)c2[nH]c3ccccc3c2CC2CN3CCCC3CC21O</smiles><smiles>CC1(C)c2[nH]c3cc(Cl)c(Cl)cc3c2CC1C1NCC23CCCN2CC1C3</smiles>

(+)-Malbrancheamide

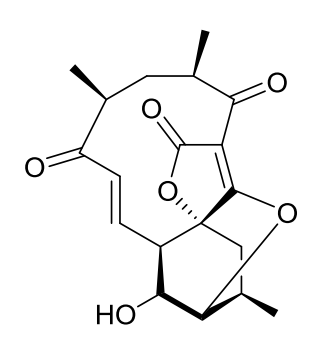

Abyssomicin $\mathrm{C}$ 

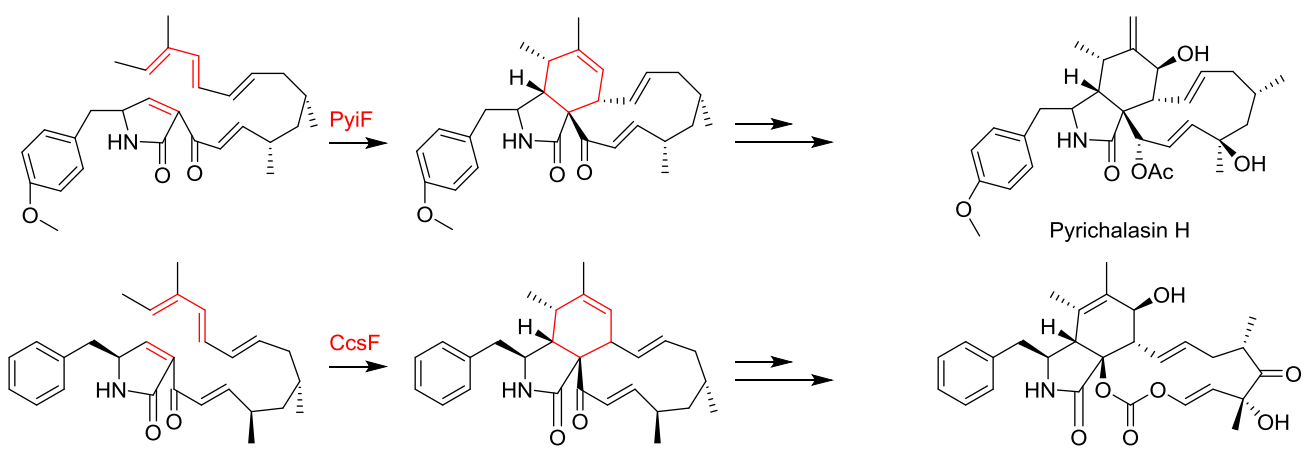

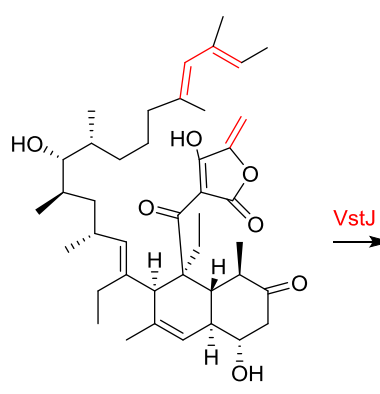

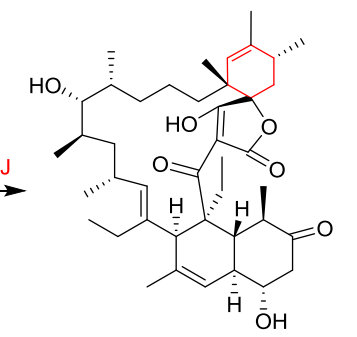

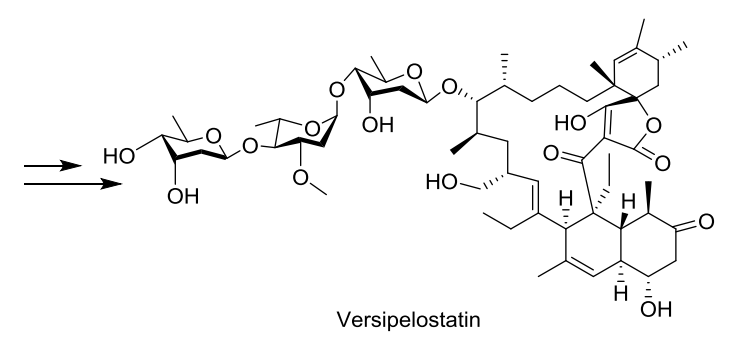

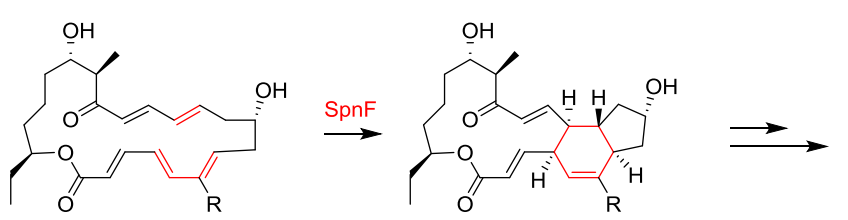

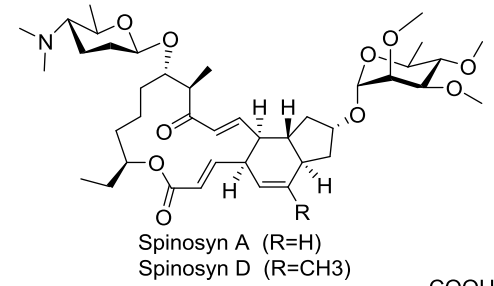

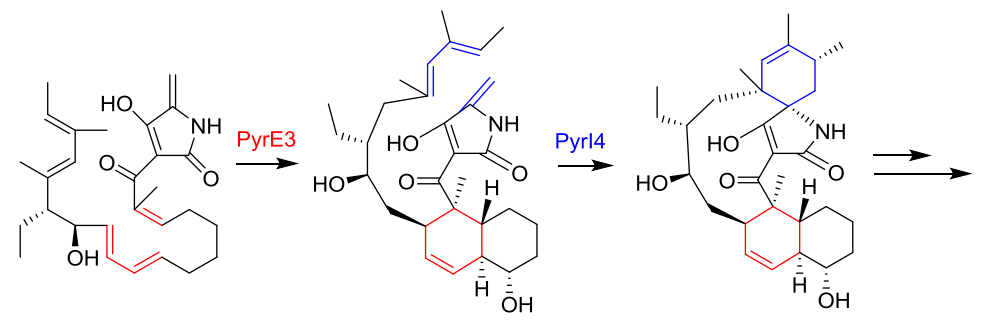

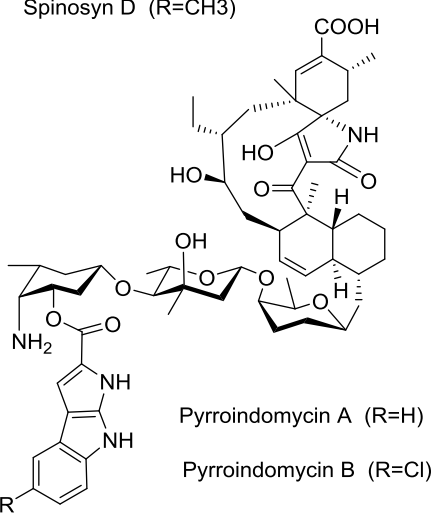



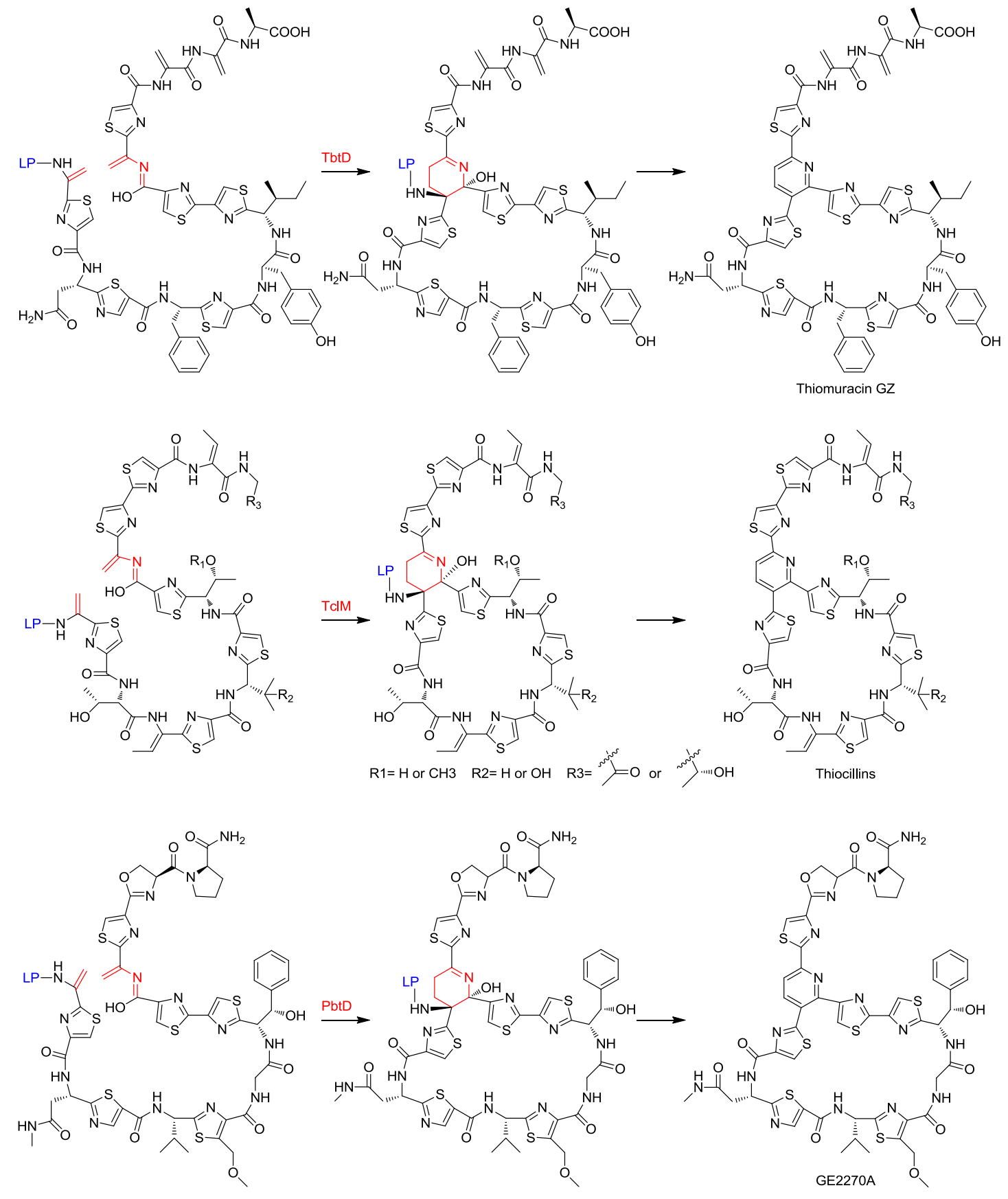
<smiles>C=C1C(=O)C=C(O)C(=O)C=C1C</smiles><smiles>C=C1OC(=O)C(=O)OC2[C@@H](O)C=C(C(=O)OC)C[C@@H]2O1</smiles><smiles>CC1=CC(C)(C)C=CC[C@]2(C)Oc3cc(O)c(=O)cc(C)c3C[C@H]2CC[C@@H]1O</smiles>
Neosetophomone B

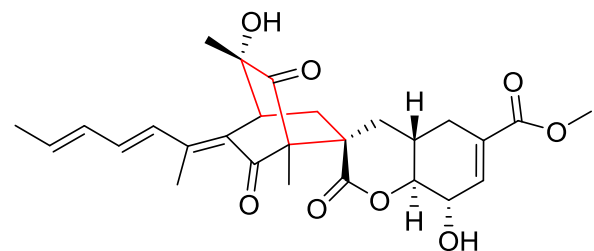

Spirosorbicillinol B<smiles>C=C(C)/C=C/c1c(O)cc(-c2cc3ccc(O)cc3o2)cc1O</smiles><smiles>CC(C)=CCc1c(O)ccc(C(=O)/C=C/c2ccc(O)cc2O)c1O</smiles>

$\stackrel{\text { MaDA }}{\longrightarrow}$<smiles>CC(C)=CCc1c(O)ccc(C(=O)O)c1O</smiles>

Chalcomoracin<smiles>O=C1C=C2OCC=C2C(=O)C=C1O</smiles><smiles>CCCCC=C(C)CC=CC(C)(C)CCCC</smiles><smiles>[134Co]</smiles><smiles></smiles><smiles>C/C1=C/CC(C)(C)/C=C/C[C@]2(C)Oc3cc(O)c(=O)cc4c3[C@@H](OC4)[C@H]2C1</smiles>

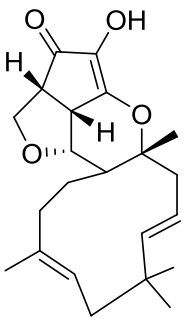

Xenovulene A<smiles>[R]N1C[C@@]2(C)c3c(nc4c(=O)[nH]c(=O)nc-4n3[R])C[C@@](C)(Nc3[nH]c(=O)[nH]c(=O)c31)N2[R]</smiles><smiles>[R9][R19]([H])([H])[H]</smiles> 
Figure S2. The SDS-PAGE analysis of purified Se-Fsa2 and Phm7.

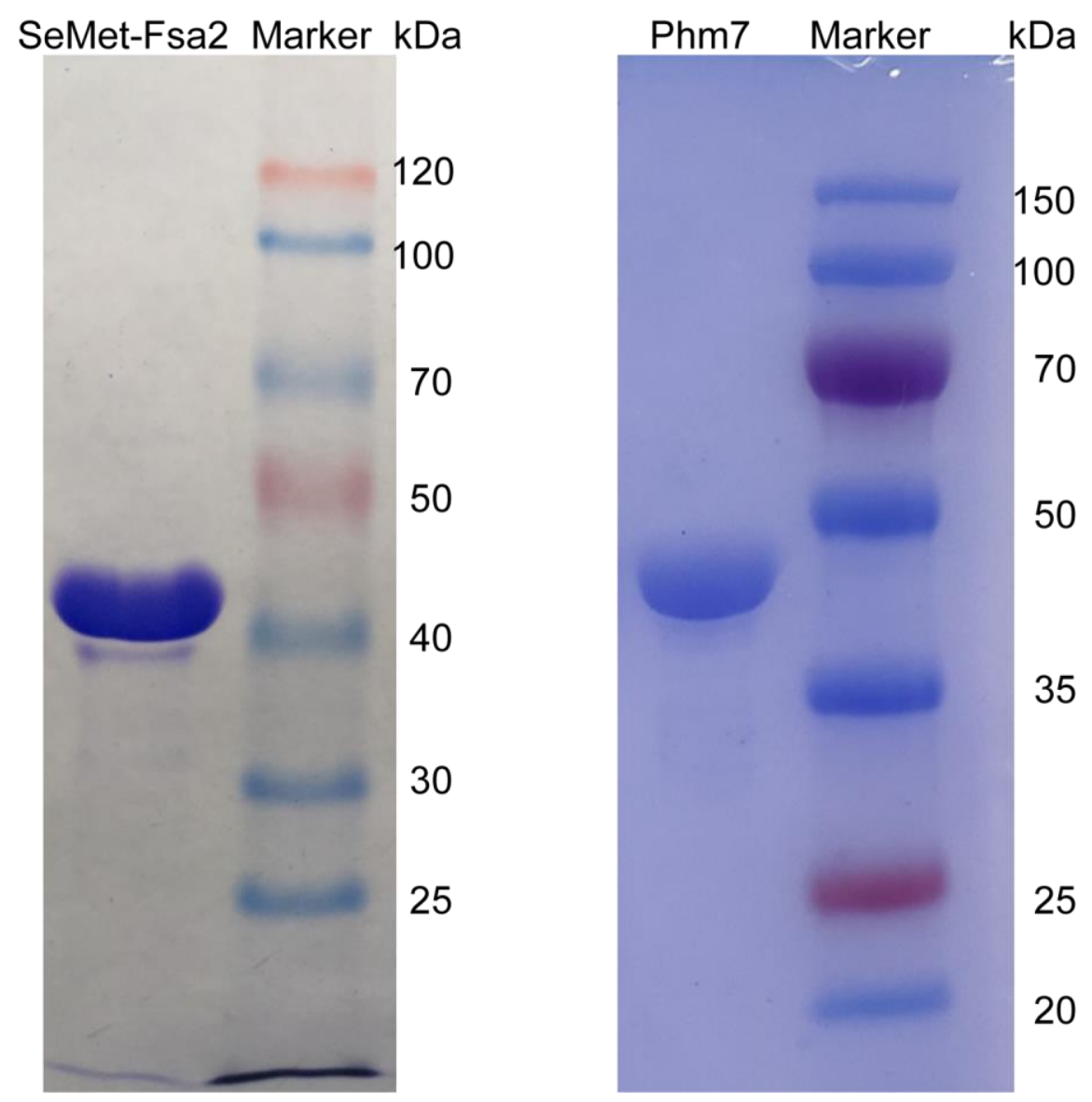


Figure S3. The $\beta$ barrels in Fsa2 and Phm7. (A) The two $\beta$ barrels in Fsa 2 are orthogonally packed with each axis perpendicular to the other. (B) The two $\beta$ barrels in $\mathrm{Phm} 7$ are orthogonally packed with each axis perpendicular to the other. (C) The long loop (green) between $\beta 1$ and $\beta 2$ covers one side of entrance of the $\mathrm{N}$-terminal $\beta$ barrel in Fsa2, and this loop interacts with another long loop (blue) between $\beta 10$ and $\beta 11$. (D) The long loop (green) between $\beta 1$ and $\beta 2$ covers one side of entrance of the $\mathrm{N}$-terminal $\beta$ barrel in $\mathrm{Phm} 7$, and this loop interacts with another long loop (blue) between $\beta 10$ and $\beta 11$.
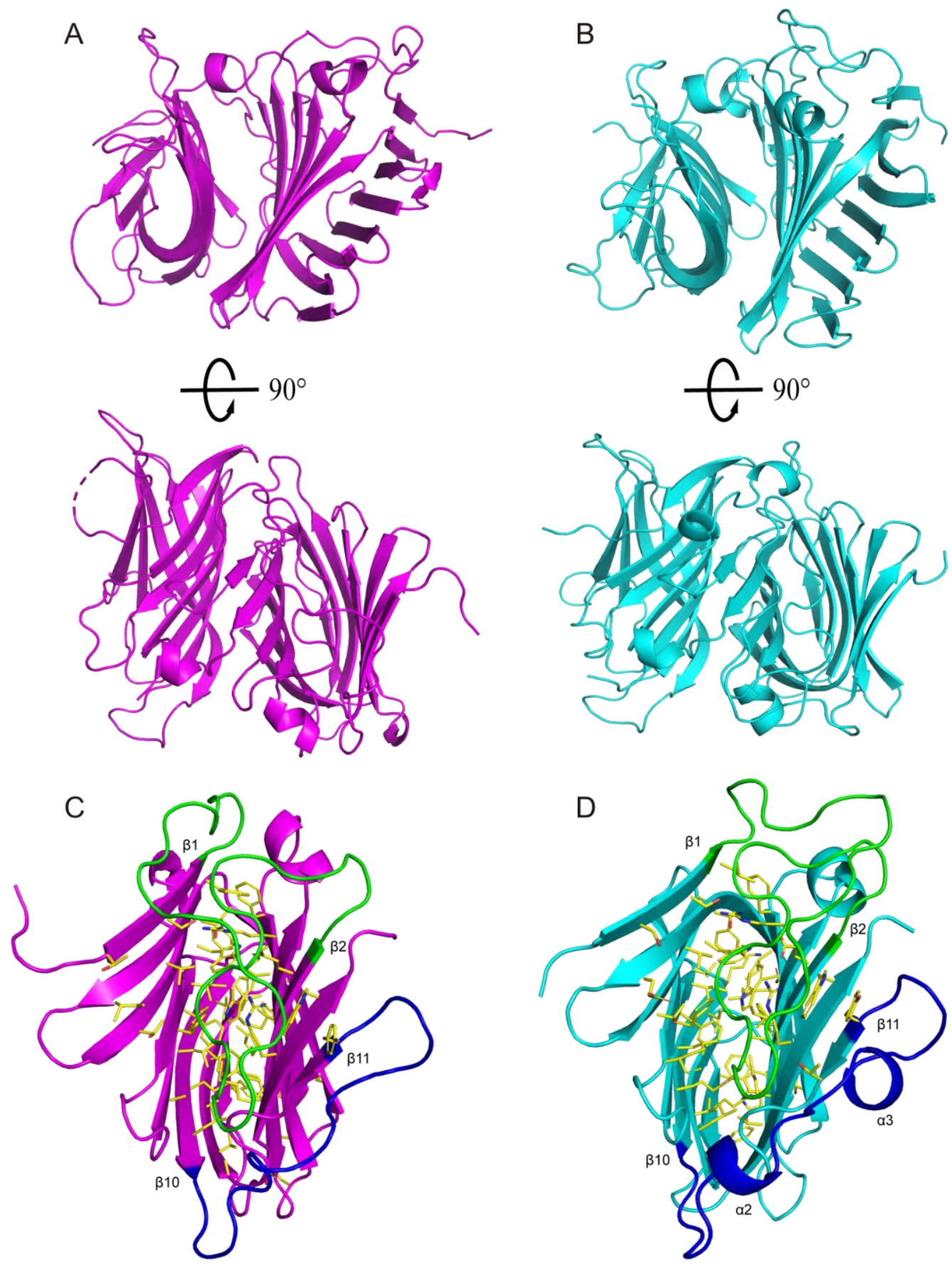
Figure S4. Structural superimposition of $\mathrm{N}$ - and C-terminal $\beta$ barrels in Fsa2 or Phm7. (A) Structural superimposition of $\mathrm{N}$ - and C-terminal $\beta$ barrels in Fsa2 gives a RMSD of $3.37 \AA$ for $108 \mathrm{C} \alpha$ atoms. (B) Structural superimposition of $\mathrm{N}$ - and C-terminal $\beta$ barrels in Phm7 gives a RMSD of $3.37 \AA$ for $108 \mathrm{C} \alpha$ atoms.
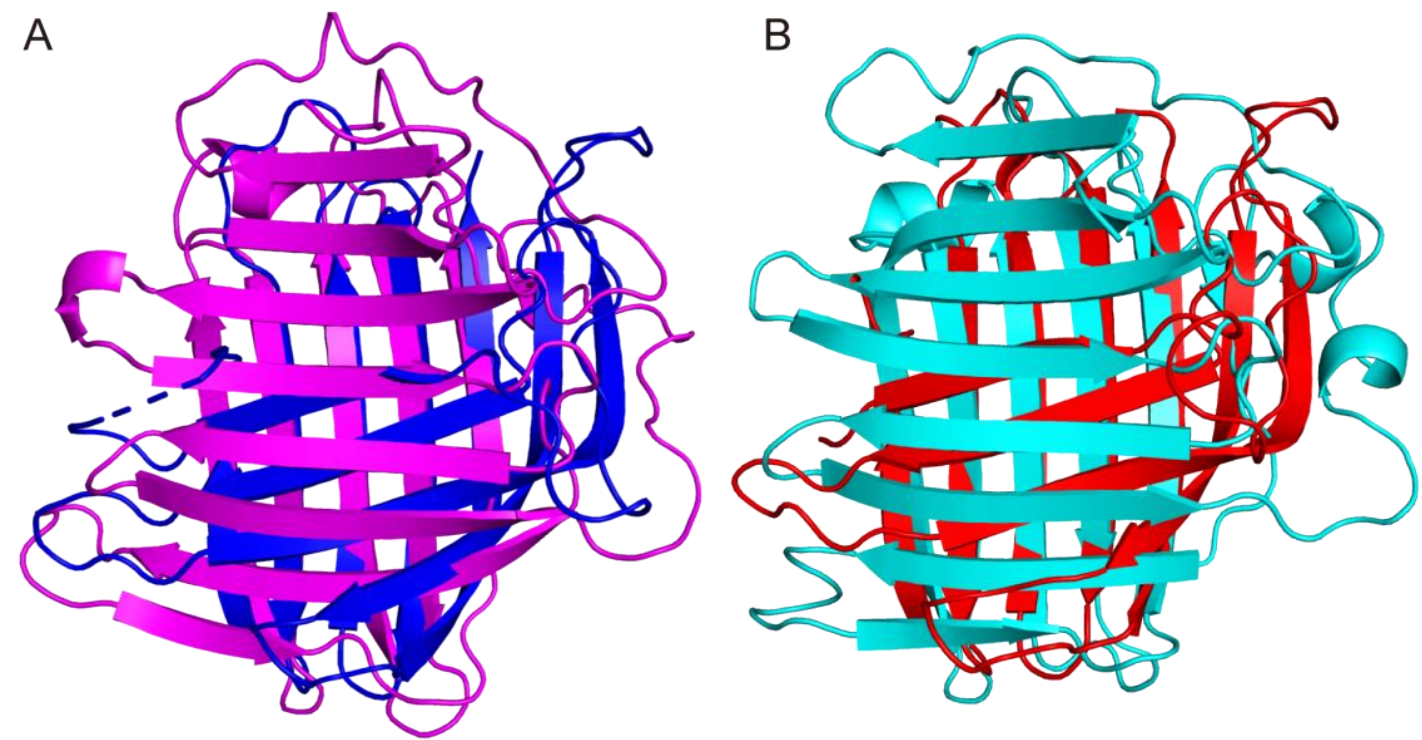
Figure S5. The six molecules in one asymmetric unit of Phm7. (A) The six molecules of $\mathrm{Phm} 7$ are shown in green, cyan, yellow, orange, red and pink in one asymmetric unit. (B) Superimposition of the six molecules in one asymmetric unit of Phm7 shows that their tertiary structures are almost the same. Colors were shown as the same to those in $(\mathrm{A})$.
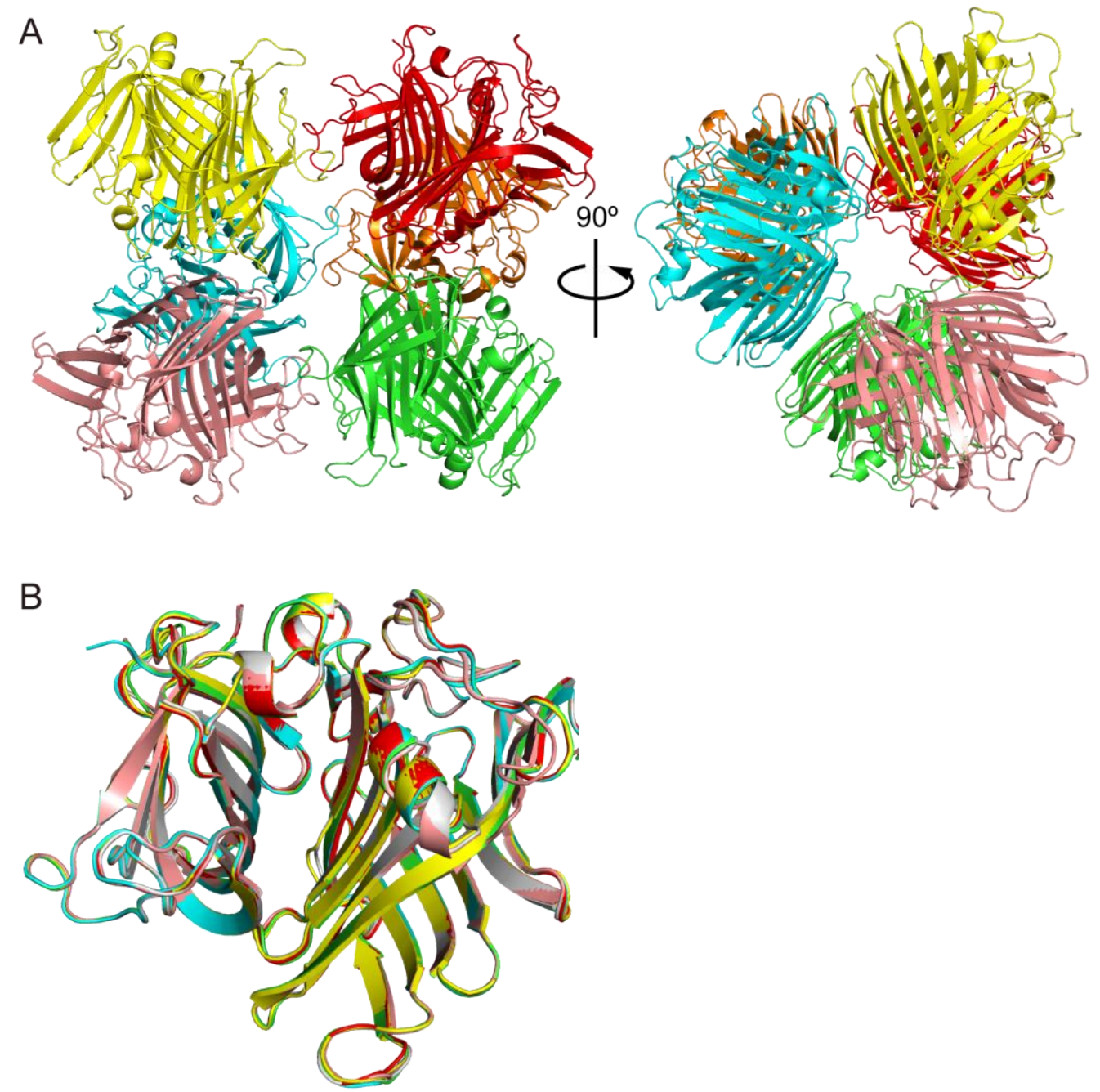
Figure S6. Sequence alignment of Fsa2, Phm7, and CghA. Secondary structure elements of Fsa2 and $\mathrm{Phm} 7$ are shown at the top and the bottom, respectively. The sequences of Fsa2, CghA and Phm7 are from the following organisms: Fusarium sp. FN080326 (Fsa2, A0A0E4AYE7.1), Chaetomium globosum strain ATCC 6205 (CghA, EAQ90433.1), Pyrenochaetopsis sp. (Phm7, BBC43190.1).

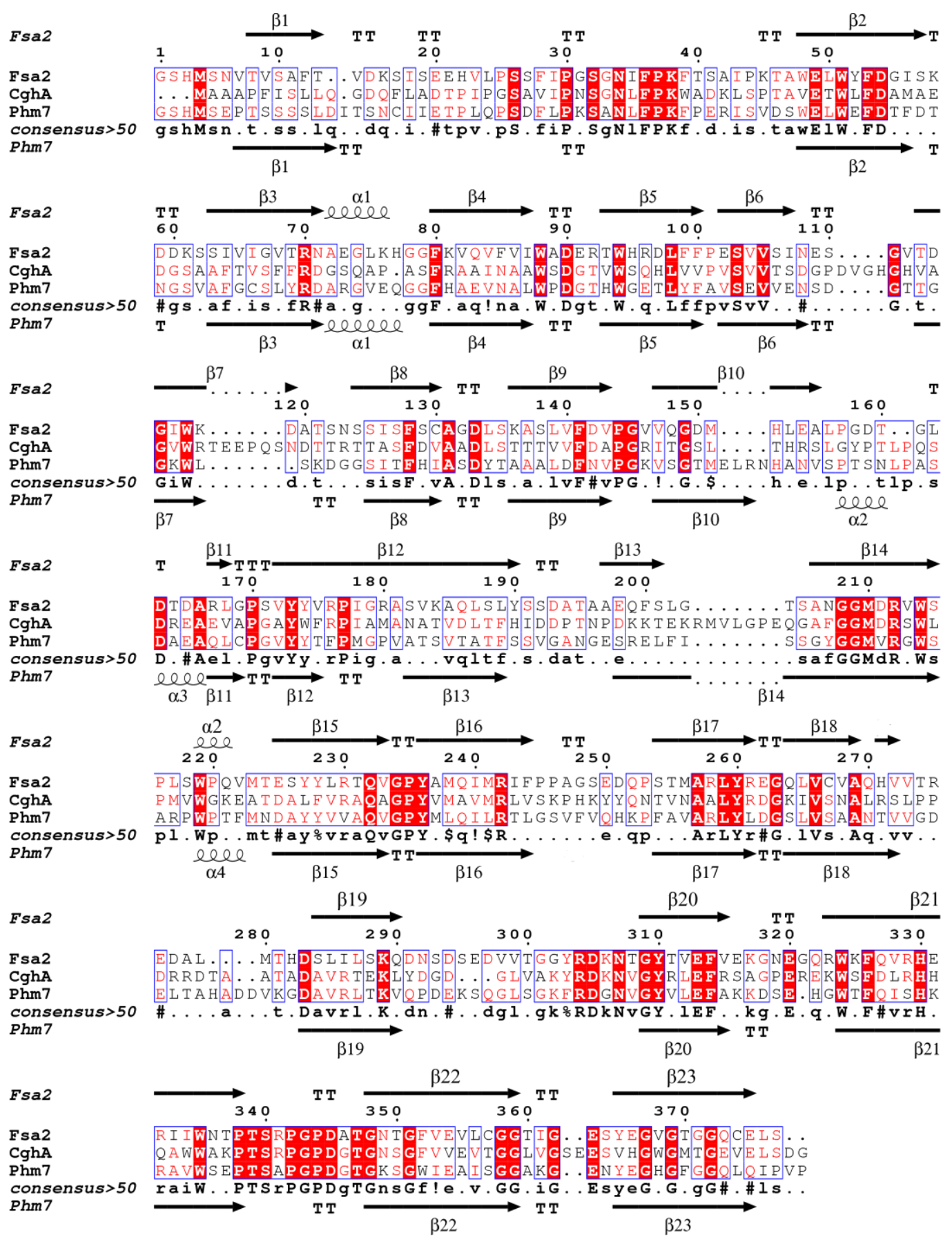


Figure S7. Structural comparisons of N- and C-terminal $\beta$ barrels of Fsa2 with PyrI4, AbyU, and AbmU. (A) Superimposition of N-terminal $\beta$ barrel (magenta) of Fsa2 with PyrI4 (green, PDB ID: 5BU3). (B) Superimposition of N-terminal $\beta$ barrel (magenta) of Fsa2 with AbyU (yellow, PDB ID: 5DYV). (C) Superimposition of $\mathrm{N}$-terminal $\beta$ barrel (magenta) of Fsa2 with AbmU (blue, PDB ID: 6LE0). (D) Superimposition of C-terminal $\beta$ barrel (magenta) of Fsa2 with PyrI4 (green). (E) Superimposition of C-terminal $\beta$ barrel (magenta) of Fsa2 with AbyU (yellow). (F) Superimposition of C-terminal $\beta$ barrel (magenta) of Fsa2 with AbmU (blue). All these comparisons show that the $\mathrm{N}$ - and $\mathrm{C}$-terminal $\beta$ barrels of Fsa2 are much more flattened than those of PyrI4, AbyU, and AbmU. Similar results were observed for structural comparisons of $\mathrm{N}$ - and C-terminal $\beta$ barrels of Phm7 with PyrI4, AbyU, and AbmU.
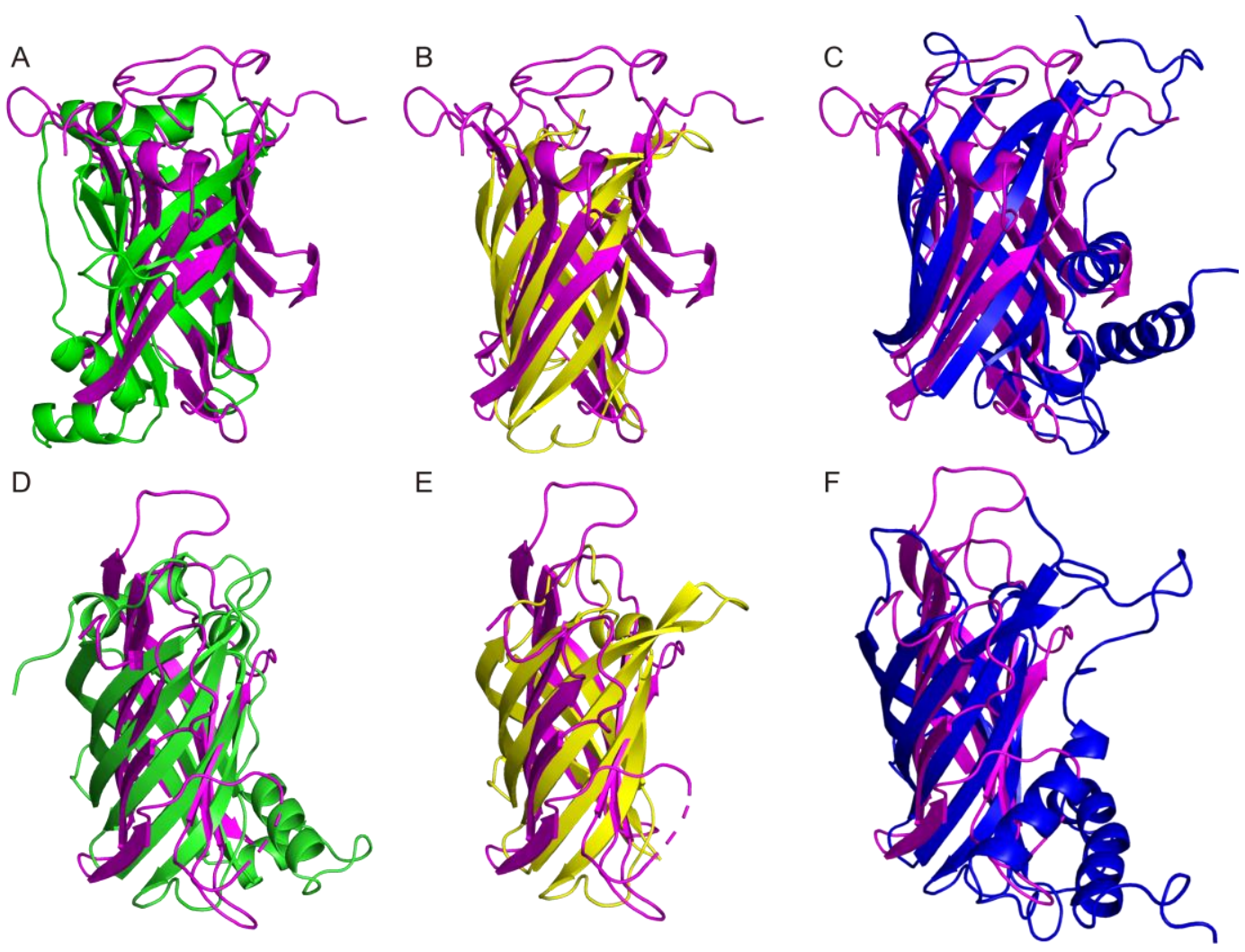
Figure S8. The two glycerol molecules in the active site of Fsa2 and their interactions with Ser226. (A) The two glycerol molecules (green sticks) in the active site of Fsa2. (B) Ser226 interacts with two water molecules (red spheres), which forms hydrogen bonds (yellow dashed lines) with the two glycerol molecules in Fsa2 structures.
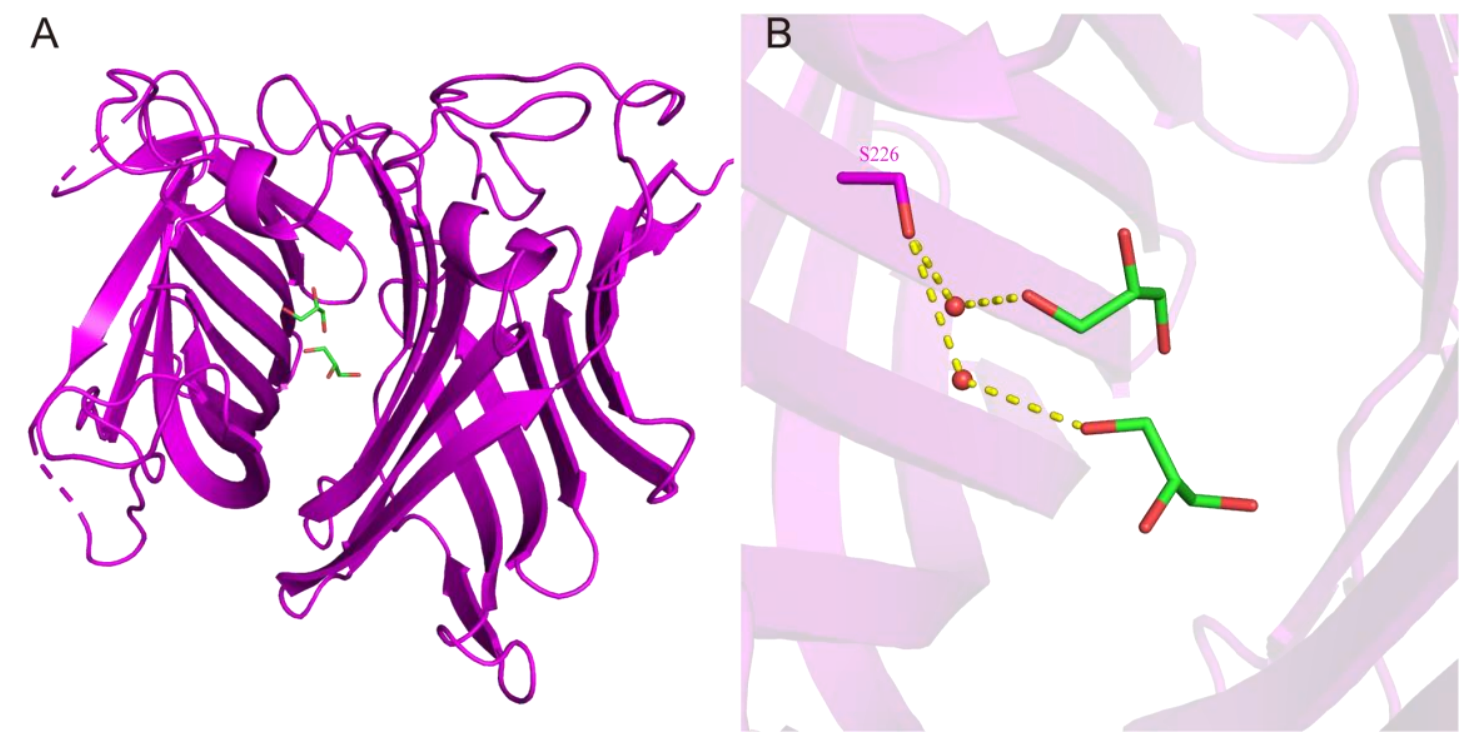
Figure S9. The products modeling into the active sites of Fsa2 and Phm7. (A) Modeling of 7 (green) in the active site of Fsa2. (B) Modeling of 6 (yellow) in the active site of Phm7. Residues' names are labelled in magenta for Fsa2 and blue for Phm7. The hydrogen bonds are indicated with yellow dashed lines.

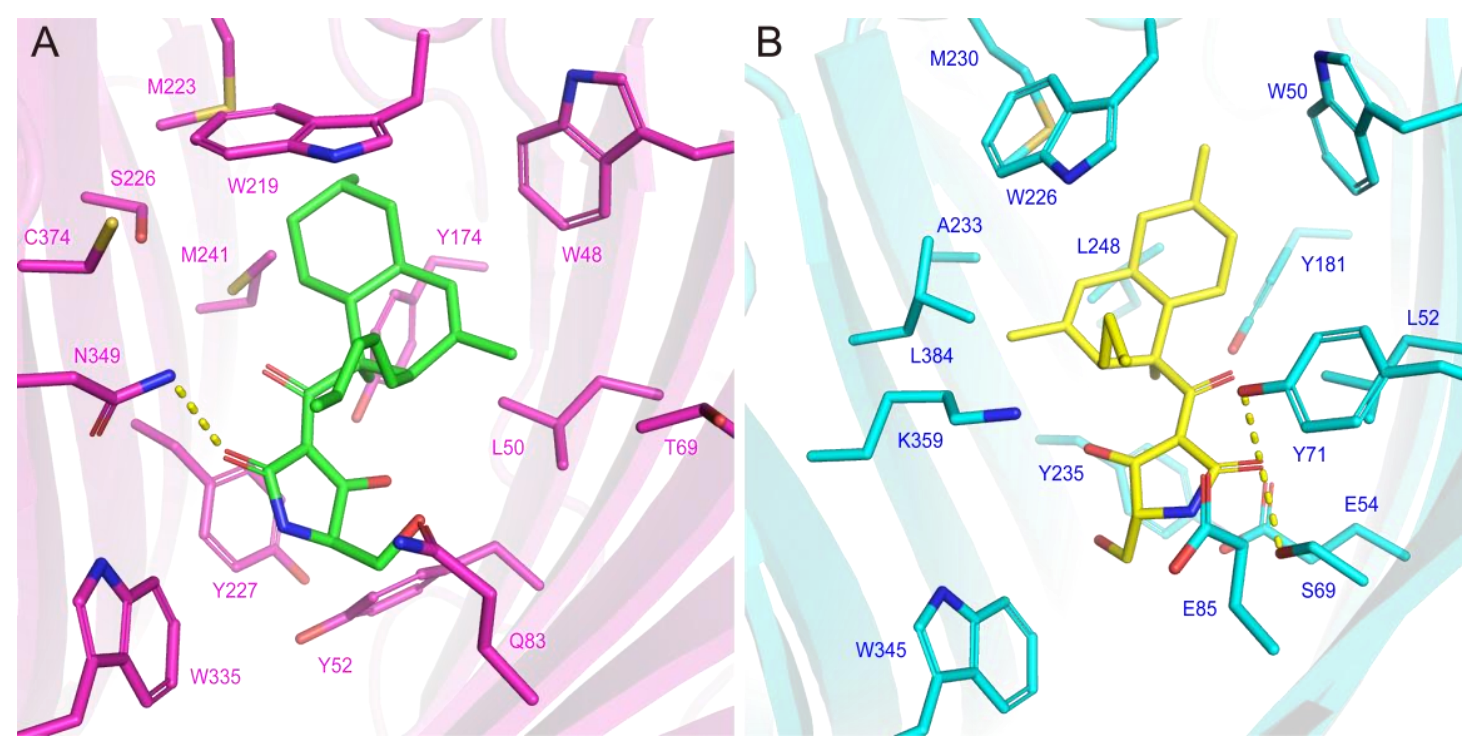


Figure S10. Comparison of the modeled 6 within the active site of $\mathrm{Phm} 7$ and the complex structure of CghA with its product Sch210972. (A) Active sites comparison of Phm7 (cyan) and CghA (orange). Residues' names are labelled in cyan for Phm7 and blue for CghA. (B) The complex structure of CghA with its product Sch210972. Sch210972 is shown in grey sticks, and hydrogen bonds are shown with yellow dashed line. (C) Superimposition of the modeled 6 (yellow sticks) within the active site of Phm7 and Sch210972 (grey sticks) in the complex structure of CghA.
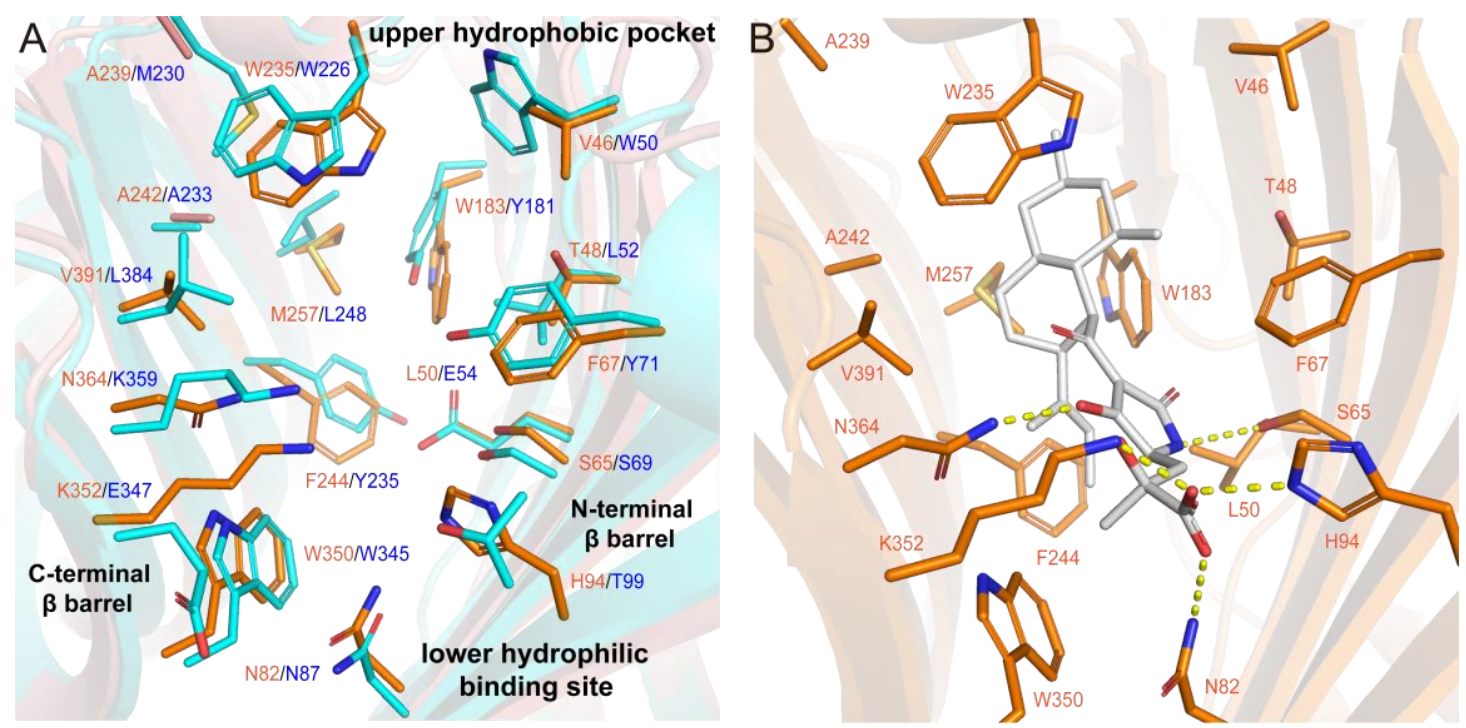

\section{C}

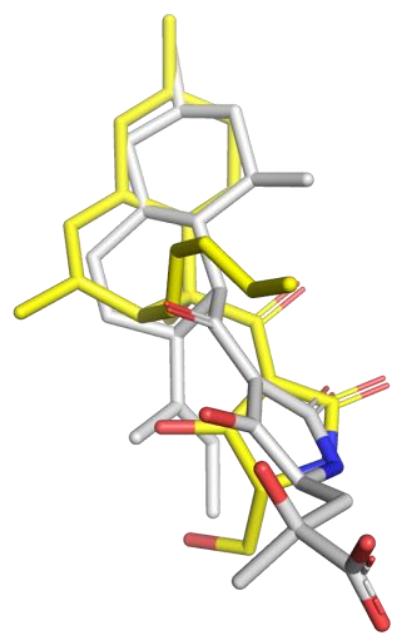


Figure S11. The molecular dynamics simulation of 5-bound Fsa2. (A) The molecular dynamics simulation of 5-bound Fsa2 (5 in cyan and Fsa2 in gray). The hydrogen bonds are indicated with yellow dashed lines. (B) Structural superimposition of 5-bound Fsa2 between molecular dynamics simulation ( 5 in cyan and Fsa2 in gray) and substrate modeling ( 5 in green and Fsa2 in magenta).

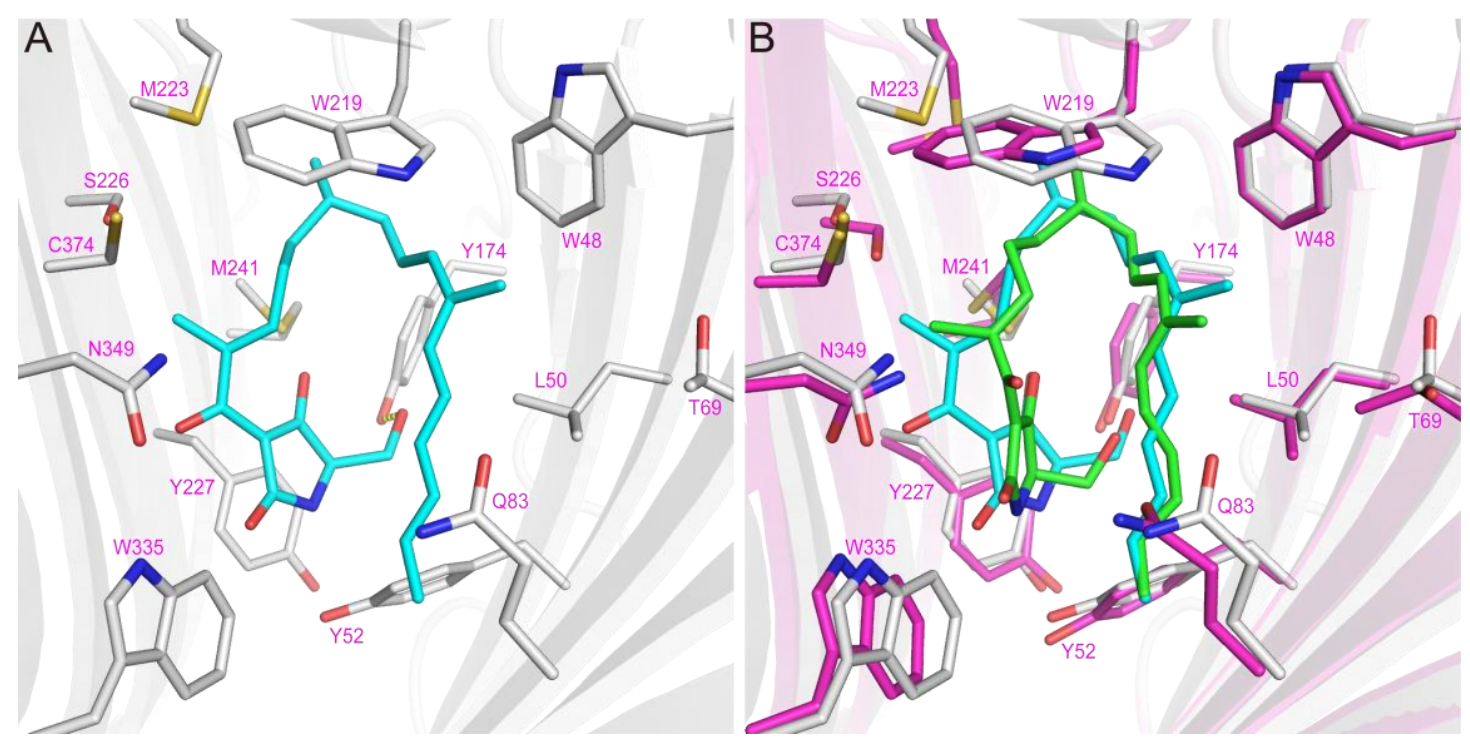


Figure S12. The molecular dynamics simulation of 5-bound Phm7. (A) The molecular dynamics simulation of 5-bound Phm7 (5 in magenta and $\mathrm{Phm} 7$ in gray). The hydrogen bonds are indicated with yellow dashed lines. (B) Structural superimposition of 5-bound $\mathrm{Phm} 7$ between molecular dynamics simulation (5 in magenta and Phm7 in gray) and substrate modeling (5 in yellow and Phm7 in cyan).

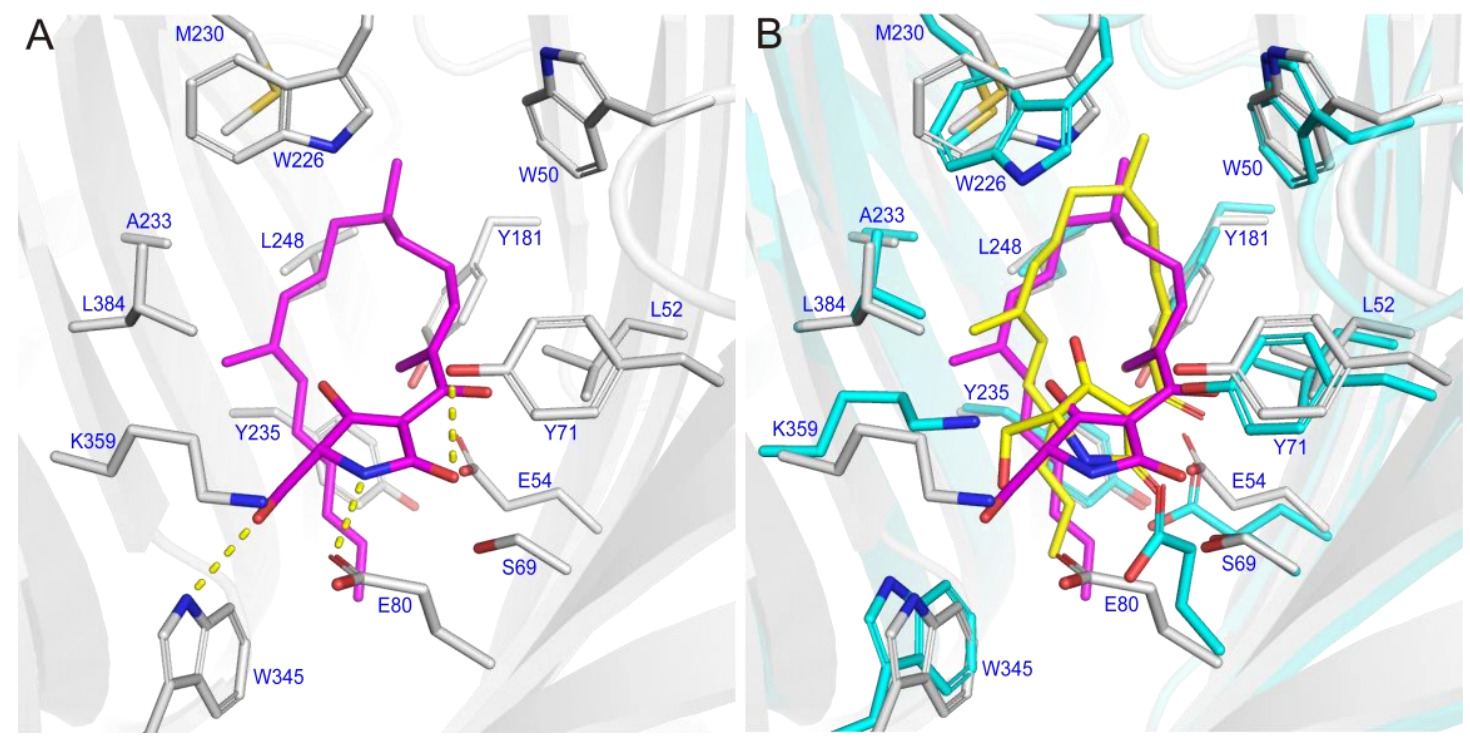




\section{Reference}

(1) Kasahara, K.; Miyamoto, T.; Fujimoto, T.; Oguri, H.; Tokiwano, T.; Oikawa, H.; Ebizuka, Y.; Fujii, I. Solanapyrone Synthase, a Possible Diels-Alderase and Iterative Type I Polyketide Synthase Encoded in a Biosynthetic Gene Cluster from Alternaria Solani. ChemBioChem. 2010, 11, 1245-1252.

(2) Li, L.; Tang, M. C.; Tang, S.; Gao, S.; Soliman, S.; Hang, L.; Xu, W.; Ye, T.; Watanabe, K.; Tang, Y. Genome Mining and Assembly-Line Biosynthesis of the UCS1025A Pyrrolizidinone Family of Fungal Alkaloids. J. Am. Chem. Soc. 2018, 140, 2067-2071.

(3) Hantke, V.; Skellam, E. J.; Cox, R. J. Evidence for Enzyme Catalysed Intramolecular [4+2] Diels-Alder Cyclization during the Biosynthesis of Pyrichalasin H. Chem. Commun. 2020, 56, 29252928.

(4) Ugai, T.; Minami, A.; Fujii, R.; Tanaka, M.; Oguri, H.; Gomi, K.; Oikawa, H. Heterologous Expression of Highly Reducing Polyketide Synthase Involved in Betaenone Biosynthesis. Chem. Commun. 2015, 51, 1878-1881.

(5) Tan, D.; Jamieson, C. S.; Ohashi, M.; Tang, M.; Houk, K. N.; Tang, Y. Genome-Mined Diels Alderase Catalyzes Formation of the cis-Octahydrodecalins of Varicidin A and B. J. Am. Chem. Soc. 2019,141, 4-8.

(6) Sato, M.; Yagishita, F.; Mino, T.; Uchiyama, N.; Patel, A.; Chooi, Y. H.; Goda, Y.; Xu, W.; Noguchi, H.; Yamamoto, T.; Hotta, K.; Houk, K. N.; Tang, Y.; Watanabe, K. Involvement of Lipocalin-like CghA in Decalin-Forming Stereoselective Intramolecular [4+2] Cycloaddition. ChemBioChem. 2015, 16, 2294-2298.

(7) Li, L.; Yu, P.; Tang, M. C.; Zou, Y.; Gao, S. S.; Hung, Y. S.; Zhao, M.; Watanabe, K.; Houk, K. N.; Tang, Y. Biochemical Characterization of a Eukaryotic Decalin-Forming Diels-Alderase. J. Am. Chem. Soc. 2016, 138, 15837-15840.

(8) Auclair, K.; Sutherland, A.; Kennedy, J.; Witter, D. J.; Van Den Heever, J. P.; Hutchinson, C. R.; et al. Lovastatin Nonaketide Synthase Catalyzes an Intramolecular Diels-Alder Reaction of a Substrate Analogue. J. Am. Chem. Soc. 2000, 122, 11519-11520.

(9) Zhang, Z.; Jamieson, C. S.; Zhao, Y. L.; Li, D.; Ohashi, M.; Houk, K. N.; Tang, Y. Enzyme-Catalyzed Inverse-Electron Demand Diels-Alder Reaction in the Biosynthesis of Antifungal Ilicicolin H. J. Am. Chem. Soc. 2019, 141, 5659-5663. 
(10) Wang, X.; Zhao, L.; Liu, C.; Qi, J.; Zhao, P.; Liu, Z.; Li, C. New Tetramic Acids Comprising of Decalin and Pyridones From Chaetomium Olivaceum SD-80A With Antimicrobial Activity. Front Microbiol. 2020, 10, 1-11.

(11) Zhang, B.; Wang, K. B.; Wang, W.; Wang, X.; Liu, F.; Zhu, J.; Shi, J.; Li, L. Y.; Han, H.; Xu, K.; Qiao, H. Y.; Zhang, X.; Jiao, R. H.; Houk, K. N.; Liang, Y.; Tan, R. X.; Ge, H. M. Enzyme-Catalysed [6+4] Cycloadditions in the Biosynthesis of Natural Products. Nature. 2019, 568, 122-126.

(12) Ohashi, M.; Jamieson, C. S.; Cai, Y.; Tan, D.; Kanayama, D.; Tang, M. C.; Anthony, S. M.; Chari, J. V.; Barber, J. S.; Picazo, E.; Kakule, T. B.; Cao, S.; Garg, N. K.; Zhou, J.; Houk, K. N.; Tang, Y. An Enzymatic Alder-Ene Reaction. Nature. 2020, 586, 64-69.

(13) Cai, Y.; Hai, Y.; Ohashi, M.; Jamieson, C. S.; Garcia-Borras, M.; Houk, K. N.; Zhou, J.; Tang, Y. Structural Basis for Stereoselective Dehydration and Hydrogen-Bonding Catalysis by the SAM-Dependent Pericyclase LepI. Nat. Chem. 2019, 11, 812-820.

(14) Ohashi, M.; Liu, F.; Hai, Y.; Chen, M.; Tang, M. cheng; Yang, Z.; Sato, M.; Watanabe, K.; Houk, K. N.; Tang, Y. SAM-Dependent Enzyme-Catalysed Pericyclic Reactions in Natural Product Biosynthesis. Nature. 2017, 549, 502-506.

(15) Drulyte, I.; Obajdin, J.; Trinh, C. H.; Kalverda, A. P.; Van Der Kamp, M. W.; Hemsworth, G. R.; Berry, A. Crystal Structure of the Putative Cyclase IdmH from the Indanomycin Nonribosomal Peptide Synthase/Polyketide Synthase. IUCrJ. 2019, 6, 1120-1133.

(16) Farrow, S. C.; Kamileen, M. O.; Caputi, L.; Bussey, K.; Mundy, J. E. A.; McAtee, R. C.; Stephenson, C. R. J.; O’Connor, S. E. Biosynthesis of an Anti-Addiction Agent from the Iboga Plant. J. Am. Chem. Soc. 2019, 141, 12979-12983.

(17) Li, Q.; Ding, W.; Tu, J.; Chi, C.; Huang, H.; Ji, X.; Yao, Z.; Ma, M.; Ju, J. Nonspecific Heme-Binding Cyclase, AbmU, Catalyzes [4+2] Cycloaddition during Neoabyssomicin Biosynthesis. ACS. Omega. 2020, 5, 20548-20557.

(18) Byrne, M. J.; Lees, N. R.; Han, L. C.; Van Der Kamp, M. W.; Mulholland, A. J.; Stach, J. E. M.; Willis, C. L.; Race, P. R. The Catalytic Mechanism of a Natural Diels-Alderase Revealed in Molecular Detail. J. Am. Chem. Soc. 2016, 138, 6095-6098.

(19) Fraley, A. E.; Caddell Haatveit, K.; Ye, Y.; Kelly, S. P.; Newmister, S. A.; Yu, F.; Williams, R. M.; Smith, J. L.; Houk, K. N.; Sherman, D. H. Molecular Basis for Spirocycle Formation in the Paraherquamide Biosynthetic Pathway. J. Am. Chem. Soc. 2020, 142, 2244-2252. 
(20) Dan, Q. Y; Newmister, S. A.; Klas, K. R.; Fraley, A. E.; Timothy, J.; Somoza, A. D.; Sunderhaus, J. D.; Ye, Y.; Shende, V. V; Yu, F.; Sanders, J. N.; Brown, W. C.; Zhao, L.; Paton, R. S.; Houk, K. N.; Smith, J. L.; Sherman, D. H.; Williams, R. M. Fungal Indole Alkaloid Biogenesis Through Evolution of a Bifunctional Reductase/Diels-Alderase. Nat. Chem. 2020, 11, 972-980.

(21) Fujii, R.; Minami, A.; Gomi, K.; Oikawa, H. Biosynthetic Assembly of Cytochalasin Backbone. Tetrahedron Lett. 2013, 54, 2999-3002.

(22) Hashimoto, T.; Hashimoto, J.; Teruya, K.; Hirano, T.; Shin-Ya, K.; Ikeda, H.; Liu, H. W.; Nishiyama, M.; Kuzuyama, T. Biosynthesis of Versipelostatin: Identification of an Enzyme-Catalyzed [4+2]-Cycloaddition Required for Macrocyclization of Spirotetronate-Containing Polyketides. J. Am. Chem. Soc. 2015, 137, 572-575.

(23) Yang, G.; Sau, C.; Lai, W.; Cichon, J.; Li, W. The Structure of SpnF, a Standalone Enzyme That Catalyzes [4+2] Cycloaddition. Nat. Chem. Biol. 2015, 344, 1173-1178.

(24) Tian, Z.; Sun, P.; Yan, Y.; Wu, Z.; Zheng, Q.; Zhou, S.; Zhang, H.; Yu, F.; Jia, X.; Chen, D.; Mándi, A.; Kurtán, T.; Liu, W. An Enzymatic [4+2] Cyclization Cascade Creates the Pentacyclic Core of Pyrroindomycins. Nat. Chem. Biol. 2015, 11, 259-265.

(25) Bogart, J. W.; Bowers, A. A. Thiopeptide Pyridine Synthase TbtD Catalyzes an Intermolecular Formal Aza-Diels-Alder Reaction. J. Am. Chem. Soc. 2019, 141, 1842-1846.

(26) Wever, W. J.; Bogart, J. W.; Baccile, J. A.; Chan, A. N.; Schroeder, F. C.; Bowers, A. A. Chemoenzymatic Synthesis of Thiazolyl Peptide Natural Products Featuring an Enzyme-Catalyzed Formal [4+2] Cycloaddition. J. Am. Chem. Soc. 2015, 137, 3494-3497.

(27) Cogan, D. P.; Hudson, G. A.; Zhang, Z.; Pogorelov, T. V.; Van Der Donk, W. A.; Mitchell, D. A.; Nair, S. K. Structural Insights into Enzymatic [4+2] Aza-Cycloaddition in Thiopeptide Antibiotic Biosynthesis. Proc. Natl. Acad. Sci. U. S. A. 2017, 114, 12928-12933.

(28) Chen, Q.; Gao, J.; Jamieson, C.; Liu, J.; Ohashi, M.; Bai, J.; Yan, D.; Liu, B.; Che, Y.; Wang, Y.; Houk, K. N.; Hu, Y. Enzymatic Intermolecular Hetero-Diels-Alder Reaction in the Biosynthesis of Tropolonic Sesquiterpenes. J. Am. Chem. Soc. 2019, 141, 14052-14056.

(29) Kahlert, L.; Bassiony, E. F.; Cox, R. J.; Skellam, E. J. Diels-Alder Reactions During the Biosynthesis of Sorbicillinoids. Angew. Chem. Int. Ed. 2020, 59, 5816-5822.

(30) Gao, L.; Su, C.; Du, X.; Wang, R.; Chen, S.; Zhou, Y.; Liu, C.; Liu, X.; Tian, R.; Zhang, L.; Xie, K.; Chen, S.; Guo, Q.; Guo, L.; Hano, Y.; Shimazaki, M.; Minami, A.; Oikawa, H.; Huang, N.; Houk, 
K. N.; Huang, L.; Dai, J.; Lei, X. FAD-Dependent Enzyme-Catalysed Intermolecular [4+2] Cycloaddition in Natural Product Biosynthesis. Nat. Chem. 2020, 12, 620-628.

(31) Schotte, C.; Li, L.; Wibberg, D.; Kalinowski, J.; Cox, R. J. Synthetic Biology Driven Biosynthesis of Unnatural Tropolone Sesquiterpenoids. Angew. Chem. Int. Ed. 2020, 2-11.

(32) Kim, R. R.; Illarionov, B.; Joshi, M.; Cushman, M.; Lee, C. Y.; Eisenreich, W.; Fischer, M.;

Bacher, A. Mechanistic Insights on Riboflavin Synthase Inspired by Selective Binding of the 6,7-Dimethyl-8-Ribityllumazine Exomethylene Anion. J. Am. Chem. Soc. 2010, 132, 2983-2990. 